\title{
EL DERECHO FUNDAMENTAL A JUSTICIA: REVISIÓN INTEGRAL E INTEGRADORA DEL DERECHO A LA TUTELA JUDICIAL EFECTIVA
}

\author{
FERNANDO MARTÍN DIZ
}




\section{SUMARIO}

I.- Planteamiento para la evolución hacia un derecho fundamental integral e integrador a la tutela efectiva de los derechos subjetivos. 1.- ¿Qué es "justicia"? 2.- Un concepto más amplio de justicia reclama un derecho fundamental integrador: antecedentes de la cuestión. II.- El derecho de acceso a justicia como derecho humano y fundamental. III.- La Administración de la justicia desde la visión integradora e integral del derecho a la justicia. IV.- Perfil procesal constitucional del derecho a justicia. 1.- Noción y aplicación del derecho fundamental procesal a justicia. 2.- Elementos jurídico constitucionales configuradores del derecho a justicia. V.- Conclusión argumental y propuesta final 


\title{
EL DERECHO FUNDAMENTAL A JUSTICIA: REVISIÓN INTEGRAL E INTEGRADORA DEL DERECHO A LA TUTELA JUDICIAL EFECTIVA
}

\author{
FERNANDO MARTÍN DIZ ${ }^{1}$ \\ Catedrático de Derecho Procesal \\ Universidad de Salamanca
}

\author{
I.- PLANTEAMIENTO PARA LA EVOLUCIÓN HACIA UN \\ DERECHO FUNDAMENTAL INTEGRAL E INTEGRADOR A LA \\ TUTELA EFECTIVA DE LOS DERECHOS SUBJETIVOS
}

En el mundo contemporáneo, en el cual se ha elevado a la máxima categoría el derecho a la autonomía de la voluntad, parece inaplazable consagrar su plasmación en la previsión constitucional que permite al ciudadano tratar de obtener protección y tutela para sus derechos a través de las formas legalmente reguladas de resolución de litigios. Advertía el jurista iberoamericano Augusto Mario Morello que el gran reto democrático es el efectivo ${ }^{2}$ acceso a la justicia ${ }^{3}$ por cuanto "cómo no ha de naufragar la gran tutela de los derechos si las pequeñas cosas (que son las que más estima la gente, porque le afectan de manera directa y sitiante) se hallan en total orfandad". La legalidad constitucional, como garante del reconocimiento de derechos fundamentales y de su protección, ampara el derecho del justiciable de resolver ante la organización pública y estatal de justicia los conflictos y litigios derivados del ejercicio y disfrute de sus derechos y libertades. Sin ir más lejos, nuestra vigente Constitución, contempla en el art. 1 como valor superior de nuestro ordenamiento jurídico a la

1 Catedrático de Derecho Procesal. Facultad de Derecho. Departamento de Derecho Administrativo, Financiero y Procesal. Campus Miguel de Unamuno. Avda. Francisco Tomás y Valiente, s/n. 37007-Salamanca. Email: fmdiz@usal.es

2 Berizonce, R.O., Efectivo acceso a la Justicia: propuesta de un modelo para el estado social de derecho, Librería Editorial Platense, 1987

3 Cappelletti, M. y Garth, B., Access to Justice - a world survey, Giuffré Editore, 1978, y Rials, A. L'accès a la justice, Presses Universitaires de France, 1993 
justicia, junto a libertad, la igualdad y el pluralismo político. La convivencia en sociedad, advertía CARNELUTTI ${ }^{4}$, depara el origen de conflictos por cuanto las necesidades humanas son ilimitadas y los bienes sobre los que recaen sus intereses son escasos. Dirimir controversias es accesible incondicionalmente, sin excepción ni discriminación por la forma personal que se ostente (sea persona física o jurídica), ni por la determinación del carácter privado o público del contendiente, ni por su nacionalidad, procedencia e incluso situación legal. El derecho a la tutela judicial efectiva que proclama en nuestro caso el art. 24 de la Constitución española vigente, es absoluto e ilimitado en este sentido.

El contenido del presente trabajo ofrece una necesaria evolución del vigente derecho a la tutela judicial efectiva ${ }^{5}$ que aloja el art. 24.1 de nuestra Constitución desde 1978. No se realiza esta apuesta por insatisfacción con los resultados jurídicos del citado derecho fundamental ${ }^{6}$, ni por sus luces o sombras ${ }^{7}$, sino partiendo del dato objetivo de que ha sido el más invocado ${ }^{8}$ ante el Tribunal Constitucional requiriendo su amparo, y desde el ejercicio responsable de hacer evolucionar los derechos fundamentales hacia el tiempo y la sociedad en que se aplican. Los excelentes resultados jurídicos del derecho a la tutela judicial efectiva, tanto en abstracto como en su desarrollo jurisprudencial ${ }^{9}$, no son óbice para remover el modelo constitucional procesal

${ }^{4}$ Carnelutti, F., Sistema del Diritto Processuale Civile, Tomo I, Cedam, Padova, 1936, p. 12

5 Cámara Villar, G., "El derecho a la tutela judicial efectiva”, Manual de Derecho Constitucional, F. Balaguer Callejón (coord.), vol 2, Tecnos, 2016, pp. 296-323; Díez-Picazo y Ponce de León, L., "Notas sobre el derecho a la tutela judicial efectiva”, Poder Judicial, núm., 5, 1987, pp. 41-49; Figueruelo Burrieza, A., El derecho a la tutela judicial efectiva, Tecnos, 1990; Gómez de Liaño González, F., "Notas sobre el alcance del Derecho a la tutela judicial efectiva", Revista universitaria de derecho procesal, núm. 0 , 1988, pp. 87-96; y Rey Rodríguez, F., "El derecho a la tutela judicial efectiva”, Constitución: desarrollo, rasgos de identidad y valoración en el XXV Aniversario (1978-2003), J.C. Gavara de Cara (coord..), JM Bosch, 2004, pp. 163-190

6 Borrajo Iniesta, I., "¿Por qué el derecho a la tutela judicial es un derecho fundamental?, Derechos fundamentales y otros estudios en homenaje al Prof. Dr. Lorenzo Martín-Retortillo, I. Aguirreazkuenaga Zigorraga (coord..), Ed. El Justicia de Aragón, vol 2, 2008, pp. 1305-13026

Jiménez de Parga y Cabrera, M., "La tutela judicial efectiva: luces y sombras", Consolidación de derechos y garantías: los grandes retos de los derechos bumanos en el siglo XXI", Ed. Consejo General del Poder Judicial, 1999, pp. 317-338

${ }^{8}$ Lo que en ciertos recursos no excluye de un desmedido abuso de su invocación, muchas veces extemporánea o directamente intempestiva o improcedente. Véase Figueruelo Burrieza, A., "Crisis constitucional y abuso del derecho a la tutela judicial efectiva”, Revista Jurídica de Castilla y León, núm. 7, 2005, pp. 129-154

9 Alonso García, E., "El art. 24.1 de la Constitución en la jurisprudencia del Tribunal Constitucional: problemas generales y acceso a los Tribunales", Estudios sobre la Constitución Española, Homenaje al Prof. E. García de Enterría, t. II, Civitas, 1991, pp. 973-1026; Bujosa Vadell, L. y Rodríguez García, N., "Algunos apuntes sobre el derecho a la tutela judicial efectiva en la jurisprudencia constitucional”, La Ley: Revista jurídica española de doctrina, jurisprudencia y bibliografía, núm., 2, 1999, pp. 1828-1840; Cabañas García, J.C., "El derecho fundamental de acceso a la justicia civil y su configuración por el Tribunal Constitucional”, Revista General de Derecho Constitucional, núm., 16, 2013, pp. 3-ss.; Calaza López, S., "Principales proyecciones del derecho a la tutela judicial efectiva en la doctrina del Tribunal Constitucional”, Revista General de Derecho Procesal, núm., 23, 2011, Garberí 
basado en el derecho a la tutela judicial efectiva hacia un derecho fundamental a justicia, más amplio, más integrador y acorde con la pujanza actual, y el previsible arraigo de futuro, de soluciones de litigios y de tutela de derechos en ámbitos extraprocesales y extrajurisdiccionales. Es, por tanto, un reto innovador a la luz de la dinámica actual del contenido constitucional directamente ligado a la protección de los derechos de los sujetos cuando estos se ven controvertidos y requieren de tutela y de obtener lo que se considera justo al respecto.

Conscientes de que los Estados modernos, democráticos y de Derecho, no pueden sino mantener y sostener la prohibición general de autotutela, cerrando el paso al desarrollo de una "justicia” privada e individual a cambio de un acceso ordenado a la obtención de justicia a través de un derecho fundamental a la tutela judicial efectiva ${ }^{10}$ para la protección de los derechos e intereses legítimos de las personas, cada vez más van asentándose alternativas no estrictamente jurisdiccionales que complementan la atribución de la Administración de la justicia al Poder Judicial ${ }^{11}$. Este fenómeno ha surgido fundamentalmente en el ámbito de los derechos disponibles y como manifestación del legítimo ejercicio del derecho a la autonomía de la voluntad que autoriza y faculta a disponer de la vía y sistema más adecuado, según el criterio de los concernidos por el litigio. Al fin y a la postre, en nuestro caso, le confiere la autodeterminación subjetiva y personal para, desde la independencia y libertad en la elección y gestión de los criterios de protección y defensa de sus derechos e intereses, decidir en relación a su disposición, uso, disfrute y a la creación, modificación o extinción de los mismos la opción jurídico-legal más conveniente para su protección y tutela con la finalidad de obtener una justa composición de dichos derechos cuando los considera vulnerados o subestimados.

La Constitución, ha de progresar hacia un derecho fundamental a justicia, a que los sujetos, cuando haya pluralidad de opciones de obtener una solución justa a una disputa, dispongan de un derecho integral. La Constitución, como cúspide del ordenamiento jurídico y referencia del mismo, aun cuando no tenga una referencia explícita e individual a todos y cada uno de los mecanismos de obtención de resolución a los litigios, ha de proporcionar un derecho fundamental amplio, integrador y orientado a la defensa de los derechos subjetivos de los ciudadanos que les permita la realización de la justicia mediante una diversidad de opciones y procedimientos legales que comprenda tanto el proceso judicial (directamente vinculado a la tutela judicial efectiva) como el arbitraje, la mediación, la conciliación, la negociación y

Llobregat, J., El derecho a la tutela judicial efectiva en la jurisprudencia del Tribunal Constitucional, Bosch, 2008, Salah Palacios, E., La tutela judicial efectiva en la jurisprudencia del Tribunal Constitucional: 19812014, Cultiva Libros, 2015 y Ruiz-Rico Ruiz, G, Carazo Liébana, M.J., El derecho a la tutela judicial efectiva: análisis jurisprudencial, Tirant lo Blanch, 2013.

${ }^{10}$ Ortells Ramos, M., y Bellido Penadés, R., "El derecho fundamental a la tutela judicial efectiva", Introducción al Derecho Procesal, M. Ortells Ramos (coord.), Ed. Thomson-Reuters Aranzadi, 2017, pp. 246-272

${ }^{11}$ Díez-Picazo Giménez, L., Régimen constitucional del Poder Judicial, Cívitas, 1991

N. ${ }^{\circ} 106$, septiembre-diciembre 2019, págs 13-42 
cualesquiera otros medios extrajudiciales y no jurisdiccionales ${ }^{12}$ de resolución de litigios. Las contemporáneas Constituciones que rigen los derechos fundamentales de los ciudadanos, surgidas al calor de la moderna democracia, reconocen y dotan de todas las garantías el derecho de los ciudadanos a resolver pacíficamente y ante la organización estatal de justicia los conflictos y litigios derivados del ejercicio y disfrute de sus derechos y libertades. No en vano, en nuestra Constitución vigente, el art. 1 propugna como valor superior de nuestro ordenamiento jurídico a la justicia.

La justicia de promoción y amparo constitucional de que disfrutamos, como sistema de Administración pública, puede y debe crecer. Al hilo de esta cuestión es oportuna la reflexión de BARONA VILAR ${ }^{13}$ en cuanto que tradicionalmente se ha venido identificando la justicia con los tribunales de justicia, con un vínculo directo al fortalecimiento del Estado, pero el significado de justicia ha sido siempre plural, diverso, expansivo y polisémico, dentro del cual se hacía referencia a la Administración de justicia, a los tribunales, al derecho constitucional moderno de la tutela judicial efectiva. Pero también, como indica la autora, la simbiosis, de plena actualidad, entre justicia e igualdad como valores del Estado moderno, en el sentido de que solo es posible la justicia si se parte de la premisa de que todos somos iguales ante la ley, nos puede deparar otro paradigma de justicia, que siempre ha existido, aunque de forma latente. Desde esa concepción, se abren paso nuevas opciones en que la igualdad ante la ley y la potenciación de la autonomía de la voluntad plantean posibilidades diferentes de acceso a la justicia, con una justicia integral, plural y diversa, pero igualmente efectiva.

\section{1.- ¿Qué es "justicia"?}

Si hablamos de un derecho fundamental a justicia, la premisa sobre la cual descansará su extensión viene dada por la intelección del concepto de justicia. En términos generales, y según las diferentes acepciones del Diccionario de la Lengua Española de la Real Academia Española, la justicia es una de las cuatro virtudes cardinales que inclina a dar a cada uno lo que le corresponde o pertenece, además de definirla como aquello que debe hacerse según “derecho o razón”. Nos encontramos, por tanto, desde una perspectiva no jurídica, con una virtud que implica la necesidad de que cada persona disponga de aquello que es suyo y que en caso de conflicto se le atribuya según normas o sentido común. La dificultad se encuentra en el momento en que dicha atribución ha de realizarse conciliando voluntades divergentes sobre una misma cuestión, sobre un conflicto, sobre una desavenencia.

12 Almagro Nosete, J., "Derecho a utilizar instrumentos jurídicos no jurisdiccionales", Sistema de garantías procesales, P. Saavedra Gallo (coord.), Dijusa, 2008, pp. 502-518

13 Barona Vilar, S., "Justicia integral y access to justice: crisis y evolución del paradigma”, Mediación, arbitraje y jurisdicción en el actual paradigma de justicia, S. Barona Vilar (coord..), Civitas Thomson Reuters, 2016, pp. 31-55 
Abordar la construcción de un nuevo derecho fundamental que podría acomodarse en una revisión constitucional de nuestra vigente Carta Magna, y que hace alusión a la justicia, requiere, indiscutiblemente, de acotar su significado desde términos estrictamente jurídico-legales. Acudimos entonces al Diccionario Panbispánico del Español Jurídico (Real Academia Española; 2017, Vol. II, p.1252). Define la justicia como un principio constitucionalmente consagrado como valor superior del ordenamiento jurídico en el que confluyen los de razonabilidad, igualdad, equidad, proporcionalidad, respeto a la legalidad y prohibición de la arbitrariedad. Concluimos con ello que cualesquiera de los medios admitidos para la realización de la justicia y desde el derecho fundamental a la misma, y con la finalidad de atribuir ordenada y pacíficamente a cada uno lo que le corresponde según las normas aplicables al supuesto de hecho, han converger necesariamente hacia toda esta serie de principios y referencias generales del Derecho anteriormente enunciados.

Hasta ahora, el derecho a la tutela judicial efectiva, como uno de los derechos de mayor calado que la Constitución confiere a sus ciudadanos, y en la interpretación jurisprudencial del propio Tribunal Constitucional ${ }^{14}$, se asociaba directamente a la idea de justicia, de obtención a través del proceso judicial de atribución de lo que legítimamente correspondía en caso de conflicto respecto a nuestros derechos o intereses. La imparable expansión y desarrollo, integrando las consecuencias que ya percibimos en la realidad, de la resolución de conflictos en sede extrajudicial está predisponiendo que el derecho a la tutela judicial efectiva deba ser reformulado y reconstruido, sobre sus bases, para dar cabida a todas aquellas formas legales que permiten al ciudadano administrar justicia a través de cauces diferentes al tradicional proceso judicial. Por ello, postulamos una evolución natural y constitucional del derecho a la tutela judicial efectiva hacia un derecho a la justicia, como derecho constitucional y fundamental que ofrezca cobertura para que el ciudadano determine libremente la elección de la solución de sus conflictos en justicia dentro de las diferentes opciones con previsión legal.

\section{2.- Un concepto más amplio de justicia reclama un derecho fundamental integrador: antecedentes de la cuestión}

La consecución de justicia se ha vinculado, en los últimos siglos y en la tradición jurídica española, prácticamente en régimen de monopolio al proceso judicial como medio a través del cual obtener tutela jurídica de nuestros derechos e intereses. Por ello se recurría como punto de partida al concepto procesal de acción ${ }^{15}$, uno de los tres

14 Bellido Penadés, R., "El derecho a la tutela judicial efectiva en la jurisprudencia constitucional", Extranjería e inmigración: Actas de las IX Jornadas de la Asociación de Letrados del Tribunal Constitucional, Ed. Centro de Estudios Políticos y Constitucionales, 2004, pp., 265-312

15 López-Fragoso Álvarez, T., "El derecho de acción como derecho a la tutela judicial efectiva", Anales de la Facultad de Derecho (Universidad de La Laguna), núm., 11, 1991, pp. 49-64, y Sánchez Barrios, 
pilares conceptuales del Derecho Procesal, concebida como derecho público subjetivo y procesal, ligado a la jurisdicción ${ }^{16}$, y configurando un derecho de acceso a la jurisdicción que se ha encarnado en el art. 24.1 de nuestra Constitución de 1978 como derecho a la tutela judicial efectiva.

Sobre la aparición del derecho a la tutela judicial efectiva hemos de apuntar que no tuvo lugar hasta la segunda postguerra mundial, por cuanto hasta ese momento únicamente se contenía en normas constitucional disposiciones relativas a las garantías del acusado en el proceso penal. Dos referencias pueden ser citadas en este sentido, como antecedentes históricos del actual derecho a la tutela judicial efectiva, cuya superación mediante un derecho a justicia más amplio e integrador, diseccionamos en este trabajo. Por un lado, el art. de la Constitución Italiana de 1947, donde por primera vez se recogía la posibilidad de que "todos podrán acudir a los Tribunales para la defensa de sus derechos y de sus intereses legítimos", derecho que se hace acompañar de una serie de garantías ${ }^{17}$ básicas: derecho a actuar en juicio para la defensa de los intereses legítimos, derecho de defensa a lo largo de todo el procedimiento, protección a los desfavorecidos para acudir ante los Tribunales, y la obligación de reparar los errores judiciales. En segundo término el art. 19.4 de la Ley Fundamental de Bonn donde se reconocía este derecho con el siguiente tenor: "toda persona cuyos derechos sean vulnerados por el poder público, podrá recurrir a la vía judicial...”, precepto que ha sido objeto de una interpretación amplia porque, aunque en principio la referencia sólo afecta a aquellas lesiones inferidas por los poderes públicos de los derechos reconocidos por éstos, doctrinal y jurisprudencialmente se extiende a todo tipo de procedimientos.

Deben reseñarse también aquí algunas normas de carácter internacional que tuvieron igualmente influencia en nuestro constituyente para la elaboración del art. 24 de la CE (Constitución Española) y que aún en la actualidad sirven, además, de referente para la interpretación del mismo. Tal es el caso del art. 10 de la DUDH (Declaración Universal de los Derechos Humanos de la Organización de las Naciones Unidas) de 10 de diciembre de 1948 ("Toda persona tiene derecho, en condiciones de plena igualdad, a ser oída públicamente y con justicia por un tribunal independiente e imparcial, para la determinación de sus derechos y obligaciones o para el examen de cualquier acusación contra ella en materia penal”); el art. 14 del PIDCP (Pacto Internacional de Derechos Civiles y Políticos de la Organización de las Naciones Unidas) de 19 de diciembre de 1966 (“... toda persona tendrá derecho a ser oída públicamente y con las debidas garantías por un tribunal competente, independiente e imparcial, establecido por la ley en la sustanciación de cualquier acusación de

M.I., "La acción como derecho a la tutela judicial efectiva", Justicia: Revista de Derecho Procesal, núm. 1-2, 2010, pp. 167-187

${ }_{16}$ Gimeno Sendra, V., Fundamentos del Derecho Procesal, Civitas, Madrid, 1981

17 Picó i Junoy, J., Las garantías constitucionales del Proceso, JM Bosch, 1997, y Chamorro Bernal, F., La tutela judicial efectiva (Derechos y garantías procesales derivados del art. 24.1 de la Constitución), Librería Bosch, 1994. 
carácter penal formulada contra ella o para la determinación de sus derechos u obligaciones de carácter civil”).

A nivel regional europeo, el art. 6 del CEDH (Convenio Europeo de Derechos Humanos) de 4 de noviembre de 1950, que aunque no regula de forma explícita el derecho a la tutela judicial efectiva ${ }^{18}$, prevé, como los artículos anteriores, el derecho a que "su causa sea oída equitativa, públicamente y dentro de un plazo razonable, por un tribunal independiente e imparcial, establecido por la ley, que decidirá los litigios sobre sus derechos y obligaciones de carácter civil o sobre el fundamento de cualquier acusación en materia penal dirigida contra ella”, de lo cual se infiere fácilmente el derecho a la tutela judicial efectiva. En idéntica línea se enmarca, para el ámbito regional iberoamericano, el art. 8 de la CADH (Convención Americana de Derechos Humanos - Pacto de San José) de noviembre de 1969.

Partiendo de todos estos antecedentes, el constituyente español de 1978 procedió a reconocer este derecho. Bien es cierto que no siempre fue así ni histórica ni constitucionalmente. Sin entrar en mayores disquisiciones, medios extrajudiciales de resolución de conflictos como el arbitraje o la mediación presentan orígenes históricos tan remotos como el propio proceso judicial. En la Grecia clásica, Platón, en su obra Las Leyes, determinaba que "los primeros jueces serán los que el demandante y el demandado hayan elegido de común acuerdo, a quienes el nombre de árbitro conviene mejor que el de jueces", dando carta de naturaleza, ya desde entonces, al invocado anteriormente principio de autonomía de la voluntad en su doble vertiente de elección por las propias partes contendientes del sistema a través del cual dirimen su controversia, así como permitiendo igualmente que elijan, asimismo, a la persona que resolverá de manera vinculante el litigio. El arbitraje constituía el medio de resolución de conflictos entre ciudades de Mesopotamia, 3.000 años A.C., y aparece recogido en textos romanos como en el Código Justiniano o la Ley de las XII Tablas. En lo que concierne a la mediación y a la conciliación, ya Confucio había introducido estos medios en la China Antigua.

Fijando la referencia en un ámbito más local y cercano, como es nuestra historia constitucional, la Constitución de 1812 (vulgarmente conocida como La Pepa), uno de los distintivos legislativos del liberalismo español del siglo XIX, dedicaba tres artículos al sistema extrajudicial de resolución de $\operatorname{conflictos}^{19}$. Circunstancia ésta que, como antecedente, bien puede servir de referencia para una reforma constitucional de futuro en la cual acoger en su seno estas variantes procesales de obtención de justicia desde un derecho, como el que propugnamos, a la justicia. Un derecho en el cual

18 Véase al respecto: Consejo de Europa y Agencia de los Derechos Fundamentales de la Unión Europea, Manual sobre el derecho europeo relativo al acceso a la justicia, Oficina de Publicaciones de la Unión Europea, 2016 y Milione, C., El derecho a la tutela judicial efectiva en la jurisprudencia del Tribunal Europeo de Derechos Humanos, Tirant lo Blanch, 2015.

19 Polo Martín, R., “Algunas consideraciones sobre la resolución extrajudicial de conflictos entre 1808 y 1881”, Mediación en la Administración de Justicia: implatación y desarrollo, F. Martín Diz (dir.), Andavira Editora, 2017, pp. 21-63

N. ${ }^{\circ} 106$, septiembre-diciembre 2019, págs 13-42 
tenga cabida para el ciudadano el acceso a la justicia desde el proceso, heredero de la mención a la tutela judicial efectiva de 1978, y también desde las vías extrajurisdiccionales de resolución de litigios que el contemporáneo siglo XXI va engastando en la Administración de justicia como servicio público. Recordamos entonces el art. 280 de la Constitución de 1812 en cuyo texto se preceptuaba que no se podría privar "a ningún español del derecho de terminar sus diferencias por medios de jueces árbitros, elegidos por ambas partes”. La citada previsión constitucional era expresión clara y fehaciente de la doble vertiente inspiradora del principio de autonomía de la voluntad cuya plasmación reclamamos para una revisión constitucional del vigente derecho fundamental a la tutela judicial efectiva y su transformación en el integrador derecho fundamental a la justicia. Habilitaba la elección de la opción del arbitraje mediante elección de las partes, así como la designación del tercero imparcial que asumía la función de impartir justicia. Completaba la referencia constitucional con el art. 281 en el cual se establecía que "la sentencia (sic) que dieren los árbitros se ejecutará si las partes, al hacer el compromiso, no se hubieren reservado el derecho de apelar — circunstancia imposible en la actualidad en el marco legislativo español vigente en materia de arbitraje ya que la única opción frente al laudo arbitral es el recurso de anulación, mecanismo impugnatorio básicamente fundamentado en motivos formales pero no de fondo como si habilita, en una orientación procesal sustancialmente diferente, una apelación-. Cerraba la trilogía normativa de la Constitución de 1812, en relación a medios extrajudiciales de acceso a la justicia, el art. 282 que contemplaba la técnica conciliatoria (o de mediación, según se interprete) como acceso a justicia a través de la función desempeñada al efecto por el Alcalde de cada pueblo, quien ejercería en su territorio municipal el oficio de conciliador o mediador "y el que tenga que demandar por negocios civiles o por injurias, deberá presentarse a él con este objeto", por tanto como obligación previa a la presentación de cualquier actuación jurisdiccional en este sentido.

Una manifestación legal, en clave de normativa autonómica sectorial, sobre la nueva e integradora visión del derecho a justicia que propugnamos la constituye la nueva Ley de Mediación de la Comunidad Autónoma Valenciana (Ley 24/2018, de 5 de diciembre), en cuya Exposición de Motivos, Apartado I, alude de forma directa al derecho de acceso a la justicia como un derecho fundamental e indispensable para la garantía y protección de los demás derechos “ya sea a través de procesos jurisdiccionales, de todos aquellos procedimientos orientados a tratar o prevenir conflictos, o de la labor de órganos no jurisdiccionales, como, entre otros, las instituciones nacionales de derechos humanos, los organismos de igualdad, y los defensores del pueblo. Existen muchos conflictos que no llegan a los tribunales y se resuelven por otras vías. Así, por ejemplo, todas las que se pueden encontrar dentro de los denominados Métodos Alternativos de Solución de Conflictos (MASC), Resolución Alternativa de Litigios (RAL) o Métodos Alternativos de Resolución de Conflictos (MARC), o Alternative Dispute Resolution (ADR), por su acrónimo en inglés, que incluyen vías alternativas como la mediación, la negociación, la conciliación, el derecho colaborativo y el arbi- 
traje. Estos métodos contribuyen al fomento de la cultura de la paz, del diálogo, de la participación, de la convivencia, de la justicia reparadora, de la escucha y del reconocimiento del otro, así como la regeneración de los lazos sociales. Además, la promoción de este tipo de mecanismos alternativos o complementarios repercute en la reducción del alto nivel de litigiosidad y sobrecarga de asuntos judiciales, contribuyendo así a mejorar la efectividad de la Administración de Justicia”.

Si acudimos al derecho comparado, podemos citar de forma muy sintética algunas referencias de nivel constitucional que pueden ser esclarecedoras al tiempo que reveladoras del avance decidido que ya se ha dado en otros Estados. Así, por ejemplo, puede citarse en primer lugar el texto vigente de la Constitución Política de los Estados Mexicanos, la cual estipula en su art. 17 que "Las leyes preverán mecanismos alternativos de solución de controversias. En la materia penal regularán su aplicación, asegurarán la reparación del daño y establecerán los casos en los que se requerirá supervisión judicial”, así como, y con un tenor muy similar, la Constitución Venezolana, en cuyo art. 258.II prevé que "La ley promoverá el arbitraje, la conciliación, la mediación y cualesquiera otros medios alternativos para la solución de conflictos".

Pues bien, en este concreto momento histórico, en la situación constitucional y de legalidad ordinaria actual, esa tutela efectiva, asignada desde el intitulado constitucional del art. 24.1 al proceso judicial, ha de dar un paso hacia adelante. Un paso hacia un horizonte más amplio de tutela jurídica, de protección jurídica, de acceso individual a la gestión de los derechos que corresponden o pertenecen legítimamente a cada ciudadano en el cual han de darse cabida de forma explícita o implícita a otras opciones ya existentes y factibles de obtener justicia. En ese sentido, las sintéticas ideas y bases que seguidamente expondremos, nos llevan a plantear decididamente la conversión y evolución del derecho fundamental constitucional a la tutela judicial efectiva en derecho a justicia.

\section{II.- EL DERECHO DE ACCESO A JUSTICIA COMO DERECHO HUMANO Y FUNDAMENTAL}

El reconocimiento internacional y europeo de los derechos humanos abarca también, como uno de ellos, el acceso a la justicia por parte del ciudadano y la consiguiente obligación de los Estados de garantizar dicho derecho, ya sea ante órganos jurisdiccionales ${ }^{20} \mathrm{o}$, con o sin circunstancias condicionantes, a otro tipo de procedimientos, organismos y entidades de resolución extrajudicial de litigios, ante los cuales invocar sus derechos y obtener justicia.

El derecho a justicia, en estos ámbitos normativos supranacionales, se asimila al derecho de acceso a la justicia y comprende a su vez otra serie de derechos humanos de carácter fundamental, como el derecho a un proceso equitativo, reconocido en el

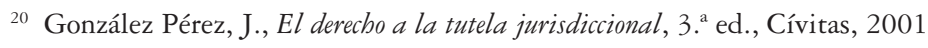


artículo 6 del CEDH y el artículo 47 de la Carta de los Derechos Fundamentales de la Unión Europea, o el derecho a un recurso efectivo según el artículo 13 del CEDH y el ya citado artículo 47 de la Carta. En la consideración jurisprudencial de estas referencias normativas europeas, se interpreta que el acceso a la justicia, tal y como determinó la Sentencia del Tribunal Europeo de Derechos Humanos en el caso Deweer v. Bélgica, de 27 de febrero de 1980, guarda plena conformidad con la existencia de sistemas extrajudiciales de resolución de controversias dentro de la proclama general del art. 6 del CEDH. Internacionalmente, el Comité de Derechos Humanos de la Organización de las Naciones Unidas ha liderado, desde sus inicios, la interpretación de los conceptos relacionados con el derecho de acceso a la justicia entre los órganos creados en virtud de tratados de la Organización de las Naciones Unidas, al hilo de las disposiciones, fundamentalmente, del apartado 3 del artículo 2 y el artículo 14 del Pacto Internacional de Derechos Civiles y Políticos de la Organización de las Naciones Unidas (PIDCP) y los artículos 8 y 10 de la Declaración Universal de Derechos Humanos de la Organización de las Naciones Unidas (DUDH). Elementos fundamentales de estos derechos son: el acceso efectivo a un órgano (judicial o no) de resolución de litigios, el derecho a un proceso equitativo y a la resolución diligente de litigios, el derecho a un recurso adecuado y la aplicación general de los principios de eficiencia y eficacia a la administración de justicia.

En ninguno de los ámbitos supranacionales anteriormente mencionados, el ámbito regional europeo y el universal que encarna las Naciones Unidas, y en sus instrumentos reguladores de derechos fundamentales, se prohíben o excluyen otras vías de acceso a la Justicia que sean diferentes al proceso judicial, es más, la integración de los mismos es el postulado que se mantiene en relación al derecho de acceso a la justicia. Así, una visión amplia del derecho a la justicia, como derecho humano y fundamental, contempla también la inclusión de órganos no jurisdiccionales, como instituciones nacionales de derechos humanos, organismos de igualdad, autoridades de protección de datos o defensores del pueblo u otros órganos incluso de carácter privado que facilitan vías más rápidas y procedimientos como la mediación y el arbitraje, que constituyen alternativas en el acceso a la justicia a través de las vías judiciales formales. Se valora especialmente, en clave de utilidad y efectividad del derecho humano al cual complementan y enriquecen como es el de acceso a la justicia, el que los procedimientos extrajudiciales pueden mejorar la eficacia de la justicia reduciendo la carga de trabajo de los órganos jurisdiccionales y ofreciendo a las personas una oportunidad de resolver sus litigios de manera eficaz y económica. Además de acarrear menores costes, pueden beneficiar a las personas al reducir la duración y la tensión de los procedimientos desde una relación equilibrada entre éstos y los procesos judiciales, confirmándose que la dimensión del derecho a Justicia no debe impedir a las partes de un litigio que ejerzan su derecho de acceso tanto a sistemas judiciales como extrajudiciales. 


\section{III.- LA ADMINISTRACIÓN DE LA JUSTICIA DESDE LA VISIÓN INTEGRADORA E INTEGRAL DEL DERECHO A LA JUSTICIA}

La evolución de la Administración de la justicia es imparable. Desde la primitiva autodefensa, prohibida hoy por nuestros ordenamientos jurídico legales, hasta los complejos modelos de solución autocompositiva de litigios que se nos presentan, incluyendo incluso fórmulas que superan el arbitraje y la mediación, como el medarb, el arb-med, MEDALOA (Mediation and Last Offer Arbitration), la evaluación neutral por experto, los juicios privados o los círculos de sentencias, todos ellos se han visto guiados por un nexo común: resolver un conflicto subjetivo e interpartes pretendiendo obtener la solución que los implicados en la controversia estiman es más justa según la vía elegida para ello. La Administración de la justicia también se ha movido entre la dicotomía de su carácter público y privado, discurriendo por diversas etapas en las cuales, en función de las épocas, los sistemas de gobierno y la propia configuración de la sociedad, se escoraba más hacia un lado o hacia otro.

El modelo más estructurado a nivel político y legal en los últimos años descansa sobre la Administración de la justicia desde una esfera pública, como poder estatal que se ejerce en exclusiva a través del Poder Judicial, con pleno refrendo constitucional, e indiscutible aceptación ciudadana. Pero, de un tiempo a esta parte, quizá por la confluencia simultánea de muy diversos factores, parece que se estuviera agotando el modelo "tradicional" de justicia centrada en el proceso judicial. Sin duda, circunstancias como pueden ser la creciente aspiración de los ciudadanos a la autocomposición de sus conflictos, el cierto descrédito de la Administración de la justicia por su lentitud ${ }^{21}$ carestía, formalidad..., o la complejidad de los litigios y la exigencia de verdaderos expertos en las materias a dilucidar, han contribuido a ello. Así las cosas, parece que nos podemos encontrar en el momento oportuno para plantear si el acceso a la Administración de la justicia por los ciudadanos, básicamente a través del proceso judicial y del ejercicio de la función jurisdiccional, ligado estrechamente al derecho a la tutela judicial efectiva, no se ha quedado insuficiente y que ha de ampliarse hacia un nuevo concepto, un nuevo derecho fundamental, acorde con la realidad social y el anhelo de los ciudadanos que se contrasta en el creciente acceso a vías extrajudiciales de resolución de conflictos, por tanto, a una nueva tutela no estricta y únicamente jurisdiccional de sus derechos e intereses legítimos.

El fenómeno, por tanto, en el cual nos encontramos inmersos es más una recuperación de la justicia por parte del individuo, que una externalización, e incluso privatización, de la misma desde su esfera pública de Administración de la justicia. Tampoco sin que ello presuponga, al menos a día de hoy, una reintegración total y absoluta de la justicia y su ejercicio hacia el ciudadano, sino más bien la búsqueda de un espacio común entre el monopolio estatal de Administración de la justicia a través

${ }^{21}$ Sainz de Robles y Rodríguez, F. C., "La lentitud en la justicia: tutela judicial efectiva y dilaciones indebidas”, Iuris: Actualidad y práctica del derecho, núm., 25, 1999, pp. 29-35

N. ${ }^{\circ} 106$, septiembre-diciembre 2019, págs 13-42 
de la función jurisdiccional y el protagonismo del ciudadano en la elección, e incluso actuación, en la tutela jurídica de sus derechos que la justicia debe ofrecerle como valor superior de la convivencia y el ordenamiento jurídico constitucional. Son momentos, los actuales, de pujanza de la autonomía de la voluntad, de protagonismo del ciudadano y de un cierto distanciamiento de lo público, en el ámbito de la Administración de la justicia. El acuerdo privado es una forma de hacer justicia, no cabe duda, y lo es de forma tan legítima como las resoluciones emanadas desde un sistema público de Administración de la justicia y a través de la resolución de un tercero imparcial que asume dicha función como puede ser el juez. El primer, y connatural, impulso del ciudadano es recurrir a la justicia "por mano propia”, y solo merced a posteriores esfuerzos históricos se ha ido asumiendo la idea de la justicia a cargo de la autoridad, como elemento de civilización del propio ciudadano que opta por acudir a un tribunal para tutelar y proteger sus derechos ante posibles amenazas o lesiones.

Lógicamente también han de considerarse sus desventajas. La actual Administración de la justicia, pública y estatal, está servida por profesionales y dotada de una estructura orgánica y material estable. La profesionalización en el ejercicio de la función jurisdiccional, consecuencia de la encomienda constitucional del art. 117, no está disponible en la vertiente extrajudicial de la resolución de conflictos. La ventaja de la ausencia de formalidad y de la sencillez de las formas extrajudiciales de conflictos contrasta con la estabilidad y profesionalidad de la función jurisdiccional, la cual aporta, además, seguridad jurídica y legal a todas sus actuaciones y resoluciones.

Se percibe, por tanto, el advenimiento de un tiempo de cambio. De sustancial transformación de la Administración de la justicia, que ya de por sí ha de ser dinámica y en evolución para adaptarse a la sociedad y al escenario social, cultural y económico en el cual se integra. Desde luego habrá novedades en cuanto al acceso a la misma, y también en cuanto a sus posibilidades, vertebrándose en torno a un modelo más abierto y plural, que ofrece al ciudadano alternativas y posibilidades, que le permite elegir y ser protagonista directo de la resolución de sus conflictos, que le hace partícipe de la Administración de la justicia y que incide en la dimensión social, cívica y humana de la Justicia, más que en la institucional y profesionalizada que encarna el modelo sustentado sobre la primacía del proceso judicial.

Ciertamente nuestro país disfruta de una Constitución consolidada y que desde la misma y sus mandatos se ha dispuesto un servicio público de Administración de la justicia que se ha ido perfeccionado mediante el correspondiente desarrollo legislativo. Ese desarrollo postconstitucional de nuestro modelo de Administración de la justicia se ha centrado básicamente en la resolución de conflictos y la consiguiente tutela de los derechos individuales a través de los órganos jurisdiccionales integrados en el Poder Judicial y que ejercitaban con exclusividad la función jurisdiccional (juzgar y hacer ejecutar lo juzgado entre las partes en conflicto), con excepciones que posteriormente, y poco a poco, se han ido abriendo como es el caso de la incorporación del Tribunal del Jurado (constitucionalmente prevista) o la habilitación legal de soluciones extrajudiciales de conflictos como son el arbitraje, y más recientemente la 
mediación, en las cuales, en todas ellas, es un ciudadano - no un juez profesional integrado en el Poder Judicial — quien administra justicia para aquellos otros que se la demandan, e incluso, como es el caso de la mediación, es el propio ciudadano quien a si mismo se otorga la solución que considera más justa a su conflicto.

Esta tendencia de ampliación de las posibilidades de administrar justicia, con directa participación del ciudadano, no debe ser considerada negativa tomando como base, tal y como apunta MEJÍAS GÓMEZ ${ }^{22}$, que no puede confundirse lo que significa "resolver conflictos" con lo que supone "juzgar". Es acorde, como ya hemos subrayado, con la actual pujanza de la autonomía de la voluntad de que dispone el ciudadano para la gestión de sus derechos disponibles — diferente cuestión es el ámbito de los derechos no disponibles o de todo lo relacionado con el derecho penal- Con ello la Administración de la justicia se personaliza, humaniza y socializa, mejorando su percepción ante la ciudadanía y ofreciendo nuevas formas de tutela de los derechos y de actividad personal en el marco de la Administración del Estado.

El modelo de justicia estrictamente procesal y estatalizado, en alusión a que la vía única y exclusiva de resolución de litigios, de acceso a la justicia, sea el proceso judicial dispuesto desde la Administración de justicia ofrecida por el Estado ha de superarse. No cabe, ya desde hace siglos, aún sin reflejo constitucional expreso, un modelo de justicia unívoco, un modelo en que la única forma de tutela pacífica y jurídica de los derechos sea el proceso judicial y a través de la función jurisdiccional que desempeñan jueces y magistrados pertenecientes al Poder Judicial. Nos encontramos en plena transición hacia una justicia integral en la cual conviven los sistemas jurisdiccionales públicos y dependientes del Estado con mecanismos extrajudiciales de resolución de conflictos, que en unos casos son antecedente preventivo e incluso alternativo al proceso (obligatorio o no) y, en otros casos, pueden complementarle en el sentido en que BARONA VILAR cataloga como "justicia compartida”.

En este punto es importante traer a colación la reciente doctrina del Tribunal Constitucional, en Sentencia $1 / 2018$ de 11 de enero ${ }^{23}$, en la cual reitera el carácter irrenunciable e indisponible del derecho a la tutela judicial efectiva del art. 24.1 CE, pero admitiendo inmediatamente que ello no impide, en legítimo ejercicio de la autonomía de la voluntad, que sea constitucionalmente válida "la voluntaria y transitoria renuncia al ejercicio de las acciones en pos de unos beneficios cuyo eventual logro es para el interesado más ventajoso que el que pudiera resultar de aquel ejercicio”. Nuestro Tribunal Constitucional, en asunto en que se ventilaba la constitucio-

22 Mejías Gómez, J.F., La mediación como forma de tutela judicial efectiva, El Derecho Editores, 2009, p. 59, aclarando con nitidez que "aunque la jurisdicción constituya la última ratio a la que todos los ciudadanos podrán acudir para obtener la tutela judicial efectiva de sus derechos e intereses legítimos, nada puede objetarse a la existencia de otros procedimientos de solución y gestión de los conflictos.

${ }^{23}$ Véase Martínez Galloso, M.N., "Comentario a la sentencia del Tribunal Constitucional 1/2018, sobre arbitraje obligatorio en el seguro de asistencia judicial”, Revista General de Derecho del Trabajo y de la Seguridad Social, núm., 49, 2018 
nalidad de un precepto que establecía una suerte de arbitraje obligatorio, desplaza claramente la decisión del ciudadano de obtener justicia hacia la propia voluntad de una de las partes que integran la relación jurídica de la cual puede surgir el litigio. Por tanto, acudir a arbitraje, mediación, conciliación o negociación, para tutelar la eficacia de un derecho disponible, es una muestra palpable e incuestionable de acceso a la justicia de forma efectiva y eficaz. Y así lo ratificó anteriormente, entre otros pronunciamientos, el aludido Tribunal Constitucional en su Sentencia 176/1996, de 11 de noviembre, al disponer textualmente que "el derecho a la tutela judicial efectiva puede ejercitarse tanto en la jurisdicción ordinaria como mediante arbitraje. De manera que no cabe entender que, por el hecho de someter voluntariamente determinada cuestión litigiosa al arbitraje de un tercero, quede menoscabado y padezca el derecho a la tutela judicial efectiva que la Constitución ${ }^{24}$ reconoce”. Incluso, en otros pronunciamientos nuestro más alto tribunal e intérprete de la legalidad constitucional, avala la obtención de resolución a un litigio incluso en trámites extrajudiciales previos al proceso judicial como son los casos de conciliación preprocesal o la reclamación administrativa previa (STC 217/1991, de 14 de noviembre).

Únicamente hemos de requerir, también de forma cabal y escrupulosa, que la configuración de un derecho fundamental a la justicia, integrando en el mismo el acceso a vías judiciales y extrajudiciales para la resolución de litigios, se haga desde la exigencia de que todas las opciones al efecto sean mecanismos legales, normativizados, con plena garantía de seguridad jurídica y que otorgan al ciudadano autonomía de la voluntad en la elección, salvo en los supuestos en que nos encontremos con derechos indisponibles o concurran razones de interés público o seguridad colectiva que lo impidan.

\section{IV.- PERFIL PROCESAL CONSTITUCIONAL DEL DERECHO A JUSTICIA}

La vertebración constitucional de la protección jurídica de los derechos e intereses del ciudadano girar en torno al actual artículo 24 de la Constitución. Previsión constitucional que fue original en nuestro sistema jurídico por cuanto no disponía de antecedentes directos y que suplía la larga ausencia de un artículo que expresamente reconociera a los ciudadanos el derecho a acudir, en este caso, ante los órganos jurisdiccionales para hacer valer sus derechos y obtener una adecuada protección de sus intereses mediante una resolución jurisdiccional. Observamos cómo, a día de hoy, el

${ }^{24}$ En este sentido Lorca Navarrete, A.M., en su trabajo $E$ Es posible el amparo constitucional frente al arbitraje?, Instituto Vasco de Derecho Procesal, 2012, reflexiona sobre la justificación del arbitraje y su encaje constitucional dentro de la aplicación al mismo del garantismo procesal, siendo una de las expresiones de dicho garantismo, su vinculación al derecho a la tutela judicial efectiva, como opción que lo alberga, y conllevando entonces la aplicación de la extensión e interpretación que se le confiere a dicho derecho al ámbito propio del arbitraje. 
ciudadano trata de incorporar nuevas vías para resolver sus conflictos, para obtener protección y tutela de sus legítimos intereses. El acceso al arbitraje, a la mediación, a la conciliación y a otras fórmulas extrajudiciales de resolver conflictos, superaría en cierto modo los parámetros de un derecho fundamental a la "tutela judicial", que a nuestro entender empezaría a encorsetar, de alguna manera, el desarrollo de posibilidades no jurisdiccionales y por tanto de "tutela no judicial", que igualmente permiten satisfacer derechos e intereses legítimos del ciudadano en caso de conflicto. El ciudadano pretende obtener justicia, sin importarle tanto, actualmente, la sede y la forma a través de la cual consigue esta finalidad. El derecho a la tutela judicial efectiva no supone que la vía del Estado-Juez-Proceso sea obligatoria, ni tampoco que sea la única vía para la resolución de los conflictos; de este modo, el particular puede bien acudir a esta vía u optar por otros cauces diferentes que pueden ir desde las fórmulas autocompositivas hasta el arbitraje, que responde a los mismos parámetros de heterocomposición que el propio proceso jurisdiccional.

Se nos presenta, por tanto, la oportunidad de aprovechar la perspectiva de un cambio en la denominación y dimensión del, hasta la fecha, derecho a la tutela judicial efectiva. Un cambio integrador y acorde con la realidad social y jurídica del momento. El derecho a la tutela judicial efectiva, se encamina hacia un nuevo rumbo para transformarse, paralelamente al cambio en el modelo de justicia, en un derecho de acceso a la tutela jurídica de derechos e intereses en sentido amplio, sin que ello implique necesariamente que el ciudadano tenga que acudir exclusivamente para obtener Justicia a los órganos jurisdiccionales. La tutela judicial efectiva, como derecho fundamental, ha de expandirse hacia las demás variantes que se van integrando en la Administración de la Justicia, y por lo tanto transformarse en "derecho a justicia”. Se trata, en definitiva, de ampliar, integrar, reforzar y fortalecer con el reconocimiento constitucional a otras opciones que complementen a la vía jurisdiccional, y hacia las cuales se puedan derivar con total garantía y seguridad jurídica determinados conflictos en aquellos casos y situaciones en que el justiciable, libremente, considera más adecuada la solución en un marco no jurisdiccional.

Es más, el propio marco constitucional nos ofrece otra serie de apoyos solventes al planteamiento que deducimos en esta propuesta. El derecho a la tutela efectiva de la justicia se asienta, entre otras razones y como ya hemos señalado con anterioridad, en el ejercicio individual y libre de la autonomía de la voluntad de los ciudadanos a la hora de elegir la vía legal que consideren más adecuada para la tutela jurídica de sus derechos e intereses legítimos. Pues bien, hemos de recordar nuevamente que el art. 1.1 de la Constitución Española establece con meridiana claridad como valores superiores del ordenamiento jurídico a la libertad y a la propia justicia, conjunción por tanto, que en nuestro caso, se asocia perfectamente a esta idea nuclear que elaboramos de que el ciudadano tenga la opción de acceder a la justicia, y administrarla a sus asuntos, desde la libertad de elección, para lo cual se requiere, a nuestro entender, de un derecho fundamental integrador, que vaya más allá de la tutela "judicial” efectiva, y por tanto acoja, explícita o implícitamente, otras posibilidades además de la 
jurisdiccional, y que también estén implementadas legalmente con la finalidad de defender y tutelar jurídicamente los derechos e intereses de los ciudadanos. Así por ejemplo, y en relación con lo expuesto sobre el art. 1.1 CE, nuestro Tribunal Constitucional, en materia de arbitraje, en STC 176/1996, de 11 de noviembre, determinó que "su función como medio heterónomo de arreglo de controversias que se fundamenta en la autonomía de la voluntad de los sujetos privados; lo que constitucionalmente le vincula con la libertad como valor superior del ordenamiento (art. 1.1 CE) de manera que no cabe entender que, por el hecho de someter voluntariamente determinada cuestión litigiosa al arbitraje de un tercero, quede menoscabado y padezca el derecho a la tutela judicial efectiva que la Constitución reconoce a todos una vez elegida dicha vía ello supone tan sólo que en la misma ha de alcanzarse el arreglo de las cuestiones litigiosas mediante la decisión del árbitro”.

La libertad de elección, autonomía de la voluntad y protagonismo del ciudadano al concederle, dentro de los límites ${ }^{25}$ y premisas legales, la posibilidad de decidir cómo obtener justicia, que en conjunción han de ser valorados positivamente. Nuestras sociedades, en estados democráticos modernos y de Derecho, están perfectamente capacitadas para asumir esta concesión. Una de las cuestiones fundamentales de la convivencia en sociedad es la de dotar a la ciudadanía de procedimientos pacíficos para solucionar conflictos jurídicos, siempre y cuando se haga dentro de las coordenadas que establece un sistema constitucional de Administración de la justicia. Al igual que el ciudadano despliega diariamente sus facultades de elección en los diferentes aspectos de su existencia, el hecho de que, conforme a su sentido común, a su razón, a sus preferencias y necesidades, opte voluntariamente por una determinada vía para la tutela jurídica de sus derechos, no debería ser visto con malos ojos. Elección del ciudadano que además no se debe ser interpretada como renuncia ni conllevar una situación real de indefensión. Incluso desde el vigente art. $24 \mathrm{CE}$, cuando, según PEREZ-UGENA COROMINA ${ }^{26}$, contiene un mandato dirigido al Poder Público para que garantice que las personas, en el ejercicio de sus derechos e intereses legítimos, obtengan de los Jueces y Tribunales una tutela judicial efectiva. La realidad evidencia la existencia y cada vez mayor desarrollo de los sistemas alternativos de resolución de conflictos al margen del procedimiento ordinario de actuación de Jueces y Tribunales. Si las partes en un conflicto deciden voluntariamente, en uso de su libertad, renunciar al derecho de someter a la actividad jurisdiccional de jueces y tribunales la controversia que les afecte en ejercicio del derecho recogido en el artí-

${ }^{25}$ Gil-Robles y Gil-Delgado, A., Los nuevos límites de la tutela judicial efectiva, Centro de Estudios Constitucionales, 1996

${ }^{26}$ Pérez-Ugena Coromina, M., "Garantía del derecho a la tutela judicial efectiva en los sistemas principales de resolución de conflictos alternativos: arbitraje y mediación”, Estudios de Deusto, vol. 62/1, 2014, pp. 159-189 
culo $24 \mathrm{CE}$, y someterla a alguno de los sistemas alternativos mencionados, esta renuncia no debe conllevar a una situación real de indefensión ${ }^{27}$.

Consideramos por tanto factible y recomendable superar el actual derecho a la tutela judicial efectiva mediante su transformación en "derecho a justicia". Un derecho más amplio, menos formalista y estricto que el derecho a la tutela judicial efectiva, en cuanto éste último se vincula en prácticamente en exclusiva al acceso a juzgados y tribunales como vía de protección de derechos y de satisfacción de intereses. Un derecho menos "público" y más "privado", menos estatal y más individual, que hace descansar en el ciudadano la responsabilidad de la libertad de opción como derecho fundamental constitucional respecto al acceso a la justicia, ampliando el concepto y los contenidos de lo que supone administrar justicia. Se trata, ni más ni menos, de adaptarse al propio cambio cultural y social que se está produciendo, y que es directamente perceptible en relación a la resolución de conflictos. Se está abandonando paulatinamente la vetusta estructura de una Administración de justicia estatal y pública, poco eficaz a la hora de adaptarse al cambio social, económico y cultural y sobre todo poco efectiva para dar respuestas a nuevas formas de conflicto y de litigios y a nuevos problemas jurídico legales del ciudadano del siglo XXI. La apuesta por los medios extrajudiciales de resolución de conflictos son un indicador de que algo está cambiando en el modelo de Administración de la justicia y con ello, algo debe cambiar, en los derechos fundamentales constitucionales de calado procesal vinculados a la justicia y el justiciable. Al fin y al cabo, el resultado final debe ser el mismo: hacer justicia, esto es, dar o reconocer a cada uno lo que legalmente le corresponde.

El tránsito que proponemos, podría ser escalonado. En este aspecto la labor interpretativa del Tribunal Constitucional sería crucial. No en vano ya se dispone de jurisprudencia del propio Tribunal Constitucional que avala la obtención de resolución al conflicto en trámites extrajudiciales previos al proceso como pueden ser la conciliación o la reclamación administrativa previa (STC 217/1991, de 14 de noviembre). El derecho a justicia podría incluso llegar a considerarse como un desdoblamiento ampliado del actual derecho a la tutela judicial efectiva, ofreciendo de una parte el tradicional marco de protección jurisdiccional de los derechos, en la versión ya conocida del derecho a la tutela judicial efectiva, y de otra parte concediendo habilitación constitucional —indirectamente amparada por el reiteradamente aludido art. 1.1 de la Constitución al proclamar la libertad como valor superior de nuestro ordenamiento jurídico- a que los ciudadanos en el ejercicio de su autonomía de la voluntad utilicen para la tutela de sus derechos otras soluciones legales no jurisdiccionales integradas en la Administración de la justicia (arbitraje, mediación, conciliación u otras nuevas alternativas que puedan surgir fruto del progreso jurídico, económico, social o tecnológico).

${ }^{27}$ Carrasco Durán, M., El derecho a la tutela judicial efectiva sin indefensión, Thomson ReutersAranzadi, 2018 
La naturaleza jurídica de este derecho fundamental no debería diferir de la que ha mantenido el derecho a la tutela judicial efectiva, como un derecho ubicado en el núcleo duro de los derechos fundamentales (Sección 1. ${ }^{a}$ del Capítulo Segundo del Título I) y que goza del máximo techo de garantías posibles entre las que se encuentran su desarrollo mediante Ley Orgánica o el acceso al amparo constitucional como vía de protección. Parece claro, por tanto, que el derecho a justicia ha de ser un derecho fundamental constitucional, con carácter de derecho prestacional de configuración legal y que demandaría que los poderes públicos dispongan un sistema público de Administración de la justicia integrado por todas aquellas opciones legalmente establecidas para la resolución jurídica de conflictos destinadas a tutelar los derechos e intereses legítimos de los ciudadanos en cuanto realización de la justicia.

\section{1.- Noción y aplicación del derecho fundamental procesal a justicia}

Proponer un derecho fundamental constitucional de naturaleza y connotaciones procesales requiere tomar como punto de partida su configuración como un derecho prestacional $^{28}$ tal y como acabamos de indicar en la parte final del apartado precedente. Recuerda el Tribunal Constitucional, en Sentencia 1/2018 de 11 de enero, que reiteradamente ha puesto de manifiesto que el derecho a la tutela judicial efectiva —base sobre la cual erigir el derecho a justicia_ — "no es un derecho de libertad, ejercitable sin más y directamente a partir de la Constitución, sino un derecho prestacional, sólo ejercitable por los cauces procesales existentes y con sujeción a su concreta ordenación legal (SSTC 99/1985, 50/1990 y 149/1995)”. Un derecho fundamental a justicia exige la existencia y aplicación de un sistema de normas procesales que determinen, expliciten y desarrollen el ejercicio de todos aquellos medios legales y con aval constitucional para dirimir litigios y dispensar al justiciable el acceso a la resolución justa y en justicia de los mismos, sea el proceso judicial, el arbitraje, la mediación, la conciliación o cualesquiera otro, presente o futuro, con reconocimiento y ordenación legal. Administrar justicia no se limita a entender que ello comprende decidir litigios, sino que, a nuestro entender, administrar justicia es, en primer término, poder decidir la forma de obtener esa justicia, mediante la elección de la vía que se considera más efectiva para conseguirla. Estamos por tanto ante la propuesta de un derecho nuevo, más amplio e integrador que el actual derecho a la tutela judicial efectiva, más vinculado al caso concreto y al sujeto, que garantiza libertad de elección e igualdad e imparcialidad en la forma de obtención de justicia.

El derecho a justicia comprenderá la libertad, autonomía, independencia y garantía de elección del ciudadano respecto a la vía, judicial o extrajudicial, legalmente habilitada y vigente, integrada en la Administración de justicia que le permita obte-

${ }^{28}$ Véase la caracterización de los derechos de tipo prestacional que ofrece Torres del Moral, A., en su obra Derecho a la tutela judicial efectiva, en Los derechos fundamentales y su protección jurisdiccional, Colex, Madrid, 2007 
ner una tutela adecuada y efectiva de sus derechos, obligaciones e intereses respecto a los litigios o controversias que se susciten en su ejercicio o vigencia. El derecho a justicia se consolidaría como la disponibilidad constitucionalmente avalada de que goza el ciudadano, mediante el sistema público de Administración de la justicia, para resolver sus asuntos jurídicamente mediante la elección de la vía que considera que le ofrece tutela efectiva de la justicia, y poder dirimir y resolver lo que le corresponde en aplicación del Derecho.

\section{2.- Elementos jurídico constitucionales configuradores del derecho a justicia}

1.- El derecho a justicia ha de ser un derecho del individuo, un derecho subjetivo reconocido a personas físicas y jurídicas, públicas o privadas, nacionales o extranjeras, como expresión de uno de los valores constitucionales máximos de que pueden disfrutar y ejercitar en un Estado de Derecho. La elección de la vía de acceso, en aquellos conflictos y litigios sobre derechos reconocidos como disponibles por la legislación interna, en la cual desean dirimir sus disputas y tratar de obtener tutela a los derechos e intereses controvertidos ha de estructurarse sobre su consideración como derecho subjetivo. No en vano, el que supondría, llegado el caso, su antecedente, como es el derecho a la tutela judicial efectiva, es uno de los derechos subjetivos más valorados, e invocados, por el ciudadano, y en idéntica línea de desarrollo y aplicación habría de situarse el hipotético derecho fundamental a justicia.

2.- Ha de ser contemplado y reconocido constitucionalmente como un derecho público, que hace surgir en la estructura estatal la obligación de poner a disposición del ciudadano una Administración de justicia adecuada e integral en la cual tengan cabida y cobertura legal los mecanismos idóneos para ofrecer al ciudadano el acceso a la justicia, entendida ésta en sentido amplio, en cuanto a las vías tanto judiciales como extrajudiciales de resolución de conflictos $^{29}$.

3.- El derecho a justicia ha de ser implementado como un derecho netamente prestacional, deparando la correlativa obligación de los poderes públicos de poner a disposición del ciudadano, en el sistema estatal y público de Administración de justicia, aquellas opciones legalmente contempladas para la resolución de litigios y la obtención de una solución justa a una controversia dilucidada en términos jurídico-legales. El derecho a justicia es un derecho vinculado a la libertad y autonomía de la voluntad del individuo, y con ello ofreciéndole la posibilidad de gestionar litigios, en este caso, dentro de los límites legales en aras a obtener la tutela más adecuada a sus

29 En este mismo sentido se pronuncia Mejías Gómez, J.F., La mediación..., cit., p. 63 indicando que "el Estado debe proponer a los ciudadanos, a través de las leyes, aquellos sistemas de resolución y gestión de conflictos que resulten útiles y eficaces, entre los cuales destaca particularmente la mediación”. 
derechos. Es prestacional al requerir la imprescindible actividad pública del Estado en poner a disposición del individuo los marcos normativos y sistemáticos de obtención de justicia, por cuanto el individuo, por sí mismo ni puede, al estar proscrita la autodefensa o autotutela de los derechos, ni tiene capacidad para ello. Se requiere, en definitiva, la articulación, el desarrollo y la concreción de las circunstancias y contenido del derecho a justicia a través de la acción de los poderes públicos para dar adecuada respuesta a esta exigencia. En este mismo sentido se ha venido admitiendo tradicionalmente que el precedente constitucional de nuestra propuesta de derecho fundamental a justicia, como es el derecho a la tutela judicial efectiva, se ha considerado un derecho de prestación que tiene por objeto acciones que impliquen decisiones públicas o a obtener, además, en su caso, un acto jurídico estatal procedente del Poder Judicial y a través de la decisión judicial emanada de un proceso.

4.- El derecho a justicia operaría como antecedente lógico, y constitucional, del acceso al concreto medio de resolución de litigio y de tutela de los legítimos derechos e intereses del individuo. De este modo, el derecho a justicia se anuda a la determinación y tutela de derechos e interés legítimos y propios de quien los invoca y ejercita como derechos reconocidos en Derecho y de carácter legal. La efectiva obtención de justicia tendría lugar una vez se desarrolle el correspondiente mecanismo heterocompositivo o autocompositivo elegido por las partes, promovida su actividad y concluido el correspondiente procedimiento, siempre de acuerdo a las previsiones legales al respecto. En este sentido podemos aludir, como única referencia analógica, la doctrina del Tribunal Constitucional respecto al acceso al proceso judicial, estableciendo en relación con el derecho a la tutela judicial efectiva, y en el sentido anteriormente expuesto, por ejemplo en la STC 84/2000, de 27 de marzo que "el derecho de acceso al proceso constituye el primero de los contenidos del derecho a la tutela judicial efectiva y, por ello, sobre él se proyecta con toda su intensidad el principio pro actione, exigiendo un control riguroso de la decisión judicial que impide conocer de la pretensión suscitada”.

No cabría, pues, ni en atención a lo afirmado anteriormente, ni tampoco en virtud de su consideración e interpretación como derecho prestacional, que el legislador estableciese obstáculos insalvables o excesivamente rígidos que dificultasen al ciudadano el acceso a medios y mecanismos de obtención de justicia, de obtención de adecuada tutela de sus derechos e intereses individuales y dignos de protección. En este sentido, podría indicarse, de nuevo desde una interpretación analógica a lo dispuesto por el Tribunal Constitucional en su doctrina al respecto en relación a la tutela judicial efectiva y el acceso al proceso judicial, que por ejemplo la exigencia de fianzas irrazonables o desproporcionadas para la utilización de un determinado medio de resolución de conflictos cercenaría de raíz la eficacia del derecho fundamental a justicia. 
5.- El derecho a justicia se asienta sobre la legalidad de las formas en las cuales se puede obtener la misma, por tanto, desde la exigencia de la previsión normativa preestablecida por Ley y con plena adecuación a las garantías y derechos constitucionales del ciudadano, siendo entonces válidas para integrarse en la Administración de la justicia y con ello para dar virtualidad al derecho a justicia como derecho fundamental integrador y amparado y aplicado desde la legalidad.

6.- El derecho a justicia es un derecho de libre configuración por el ciudadano, quien haciendo uso de la autonomía de la voluntad, y salvo las excepciones previstas por la Ley, podrá optar libremente por la forma de solución del litigio que considere más adecuada e idónea a sus intereses y a la tutela de sus derechos y a la obtención de una solución justa y en Derecho. En este sentido el derecho a justicia no podría ser negado a ningún ciudadano y, con ello, a priori dispondría plenamente de la libre elección de la vía legal para resolver disputas. Sí podría ser restringido o condicionado en su ejercicio, fundadamente y con previsión legal expresa, ante la concurrencia de intereses de mayor y más necesitada protección que el ejercicio de este derecho fundamental, que, por ejemplo, determinaran las posibilidades de elección (impidiendo acudir a medios autocompositivos, por ejemplo) o que las redujesen obligatoriamente al cauce exclusivo del proceso jurisdiccional.

7.- Requiere, asimismo, el derecho a justicia de una correlativa exigencia con la autonomía de la voluntad de los sujetos de la mínima intervención por parte de los poderes públicos en el sentido de no coartar ni condicionar, salvo lo anteriormente expuesto, la autonomía de la voluntad de los ciudadanos en la elección de la vía de resolución de sus litigios. Los poderes públicos, básicamente encarnados en este caso por la Administración pública de justicia entendida en sentido lato, asumirían la responsabilidad de implantar y desarrollar los mecanismos jurídicos de resolución de conflictos aprobados legalmente por el Parlamento en aplicación de la política legislativa procesal impulsada desde el ejecutivo, y dotarlos de los recursos materiales y personales imprescindibles para su utilización. Con ello se mantendría el imprescindible sistema público de Administración de justicia al tiempo que se le dota de efectividad para la adecuada protección de los derechos de los sujetos. Su responsabilidad para hacer efectivo el acceso a la justicia implica poner a disposición del ciudadano una amalgama de posibilidades que puedan depararle la consecución de soluciones justas a sus litigios. Arbitraje, mediación, conciliación u otras variantes, siempre que estén legalmente reguladas e integradas en el sistema de justicia pública estatal, deben formar parte de este novedoso derecho fundamental que aquí propugnamos, un derecho con un contenido y aplicación material más amplio que el actual derecho a la tutela judicial efectiva, al cual, a día de hoy, se ven remitidas solo de forma indirecta y analógicamente. 
8.- Finalmente, el derecho de acceso a la tutela efectiva de la justicia ha de sustentarse sobre un elemento de compatibilidad interna entre las diferentes opciones legales, integradas en la Administración de la justicia, que impliquen su ejercicio eficaz. No consideramos oportunas entonces, ya que contravendrían su estructura, la elección del legislador por prelaciones o preferencias, e incluso con remisiones obligatorias $^{30}$, a determinados medios de resolución de litigios frente a otros, salvo en los casos, ya anteriormente apuntados, en que por circunstancias concurrentes para una mejor protección de un interés o valor superior deba condicionarse o limitarse la capacidad de elección del sujeto. La compatibilidad no ha de ser óbice para la evidente y natural diferencia entre los diversos medios de resolución de litigios, cada uno con sus características propias, con sus ventajas e inconvenientes, con su validez e idoneidad para cada tipo de conflicto, enlazando con ello sus inherentes condiciones particulares a la valoración personal del sujeto que ha de optar libremente por la que considere más adecuada para la protección de legítimos derechos e intereses y para su percepción personal de lo que es justicia.

\section{V.- CONCLUSIÓN ARGUMENTAL Y PROPUESTA FINAL}

La autonomía del sujeto está profundamente asentada en la cultura y en la sociedad contemporánea. En casi todos los aspectos vitales, ante cualquier circunstancia, se presentan múltiples alternativas, diferentes opciones. El dilema de resolver un conflicto, con connotaciones jurídicas, no es una excepción. Para resolver de forma jurídica y legal una situación de litigio o confrontación, disponemos de alternativas. Una, la más tradicional y asentada en nuestra tradición jurídica histórica, es el pro-

30 En este sentido el Anteproyecto de Ley de Impulso de la Mediación, presentado por el Ministerio de Justicia en diciembre de 2018, planteaba una reforma de la mediación en el ámbito del derecho privado que conllevaba la implantación de un sistema de obligatoriedad "mitigada" (en expresión del propio Anteproyecto) que configuraba como obligación de las partes un intento de mediación previa a la interposición de determinadas demandas (las relativas a materias concretas donde se establecería esta obligación se recogerían en un nuevo texto reformado del art. 6 de la Ley 5/2012, de 6 de julio), o bien cuando el tribunal en el seno de un proceso considerase conveniente que las partes acudiesen a esta figura y, en ambos casos, con la finalidad de lograr una solución más ágil y efectiva. Entraría en colisión evidente este planteamiento del Anteproyecto, con lo afirmado reiteradamente en la jurisprudencia del Tribunal Constitucional. A título de ejemplo podemos citar en este caso la Sentencia 140/2016, de 21 de julio, donde recuerda que el derecho de acceso a la jurisdicción, vertiente de aquel más general a la tutela judicial efectiva (art. 24.1 CE), es un derecho fundamental de configuración legal que, en virtud de este último carácter, conlleva un grado de libertad de actuación en el legislador para definir las condiciones y requisitos determinantes de dicho acceso en los distintos órdenes, esa tarea de configuración no se encuentra sin embargo exenta de limitaciones. De esta manera, "el derecho a la tutela judicial efectiva puede verse conculcado por aquellas normas que impongan condiciones impeditivas u obstaculizadoras (del acceso a la jurisdicción), siempre que los obstáculos legales sean innecesarios y excesivos y carezcan de razonabilidad y proporcionalidad respecto de los fines que lícitamente puede perseguir el Legislador en el marco de la Constitución". 
ceso judicial. Otras, en contraposición, al aunarse bajo el común denominador de su carácter extramuros del ámbito de juzgados y tribunales, de marcado acento extrajudicial (arbitraje, mediación, conciliación, negociación e incluso formas de nuevo cuño que combinan de forma híbrida alguna de las existentes y a las que se suman además todos los avances tecnológicos que se implementan en su utilización). Y todas, una y otras, responden a una necesidad básica del ciudadano y de la convivencia en sociedad: el derecho a justicia. Dar cuerpo a la virtud de otorgar, y respetar, lo que corresponde a cada persona. Si, tal cual, el derecho a justicia, sin la referencia del derecho "a la justicia”. Si a ello unimos que pese a la existencia de un sistema pretoriano de modificación constitucional, debe sostenerse ante todo que la Constitución no es, ni debe ser nunca, un ser estático y perenne, sino que ha de ser un texto con vida y dinamismo, al igual que la sociedad a la que orienta y guía, en cuyo ideal de virtud ha de estar presente en todo momento su adaptación constante a la realidad social, económica y cultural para cuyos integrantes ha de ordenar, desde el marco jurídico, su pacífica convivencia.

Analizando el vigente derecho fundamental a la tutela judicial efectiva, concentrado en exclusiva en su enunciado, y aplicación, en tutelar con el máximo nivel de garantía el acceso a los órganos jurisdiccionales cara a la satisfacción intereses dignos de protección jurídica, consideramos que comienza a verse superado por la concurrencia de otras vías, no jurisdiccionales, a través de las cuales los ciudadanos también pueden ver, igualmente, satisfecha la tutela de sus derechos e intereses subjetivos. La realidad supera el marco constitucional, nos ceñimos testarudamente y de forma literal al enunciado de los preceptos, al menos en el caso español y comunitario europeo de forma mayoritaria, y a que la variante para obtener justicia sea la netamente jurisdiccional, cuando se puede hacer "justicia” en diferentes sedes, modalidades y opciones, con cobertura legal, sin infracción de derechos fundamentales y de forma y manera plenamente segura a nivel jurídico. Todo ello sin que sea óbice, y así lo ha manifestado el propio Tribunal Constitucional en algunos de sus pronunciamientos, para que el ciudadano acceda, allí donde su facultad de disposición sobre el ejercicio de los derechos alcanza, a tutelar sus bienes jurídicos en opciones extrajudiciales que le otorguen la protección y tutela pretendida.

El carácter público de la Administración de la justicia debe avanzar y ampliarse en sus horizontes y posibilidades para incardinar en su integración fórmulas extrajudiciales con ciertas facultades dispositivas a los intervinientes en la resolución de un litigio. La justicia, en sentido amplio y constitucional, es un poder público, estatal y delegado funcionalmente en el Poder Judicial y, por tanto, en nuestro país y según la previsión constitucional, es un por ello servicio público, dispensado al ciudadano a través de la Administración de justicia que perfectamente puede ofrecer al ciudadano mecanismos de resolución de litigios y tutela de derechos individuales de carácter jurisdiccional como extrajurisdiccional. Únicamente hay que, encajando las nuevas opciones legales, de corte extrajudicial, en la estructura y dinámica de la Administración de la justicia y llevar a efecto las modificaciones que ello requiera, superando 
el modelo antiguo y relativamente anacrónico de una justicia exclusivamente jurisdiccional. Por ejemplo, y como uno de sus primeros pasos, por cuanto amplia el marco desde la legalidad constitucional, la que postulamos aquí, en cuanto a la transformación y evolución del actual derecho a la tutela judicial efectiva hacia un derecho a justicia. Comenzaría con este impulso, el camino hacia una justicia integral, en la que se complementa el sistema jurisdiccional con mecanismos extrajudiciales de resolución de conflictos, que en unos casos son antecedente preventivo e incluso alternativo al proceso (obligatorio o no) y, en otros casos, pueden complementarle en el sentido en que BARONA VILAR ${ }^{31}$ cataloga como "justicia compartida”.

El derecho a justicia, como ciudadanos, debe permitirnos elegir libremente cómo, cuándo y dónde resolver de forma legal, segura, ordenada, pacífica y estable nuestros conflictos. Es cierto que determinados condicionantes, algunos ya anticipados en esta opinión personal que aquí se expone, deben confluir y casar con este derecho, que no podrá ser indiscriminado y absolutamente arbitrario. El encaje del ejercicio personal y subjetivo del derecho a justicia ha de conciliarse con la integración individual de cada persona en la sociedad, es una sociedad democrática y de derecho como la que rigen las constituciones democráticas modernas. De este modo garantizar la seguridad jurídica y la protección de determinados bienes jurídicos y valores sociales que se erigen en indisponibles serán cortapisas que en determinados casos modularán o condicionarán el ejercicio del derecho a justicia o que, incluso, en algunas ocasiones impedirán su efectiva aplicación individual. Recordemos, por tanto, que, en el ámbito del derecho penal, la comisión de determinados delitos que afecten a bienes jurídicos e instituciones supraindividuales (como puede ser la protección del medio ambiente, el orden socioeconómico, la Hacienda Pública o la propia Administración de justicia) excluirán de partida la reclamación a título individual para el ciudadano del ejercicio de su derecho a justicia en estas materias. Al igual que puede ocurrir en algunas, las menos, cuestiones del derecho privado, como pueden ser las vinculadas fundamentalmente al estado civil de las personas o al ejercicio de determinados derechos civiles que puedan a afectar a menores o incapaces.

Sin duda es una apuesta arriesgada el tratar de plantear un avance tan aperturista. Despojarse de las vestiduras procesales tradicionales, de corte clásico e invariable a las distintas épocas. Primero por la inercia de cómo se reviste el proceso judicial estructurado prácticamente en única vía para obtener justicia, retomando la acepción de la Real Academia Española, otorgando a cada uno lo suyo según derecho o razón —en este caso apenas posible al postergar la equidad como fuente primaria de derecho material e incluso de derecho procesal- Pero por buena que sea la inercia que nos conduce, no ha de servir de freno al progreso. Hemos de acomodarnos a las realidades de los nuevos tiempos, a otras opciones y estilos, de corte autocompositivo y heterocompositivo como son la conciliación, negociación, mediación, arbitraje, incluso las más avanzadas e híbridas como el med-arb, el arb-med o el MEDALOA, o las más

31 Barona Vilar, S., "Justicia integral ...", cit., pp. 51-ss 
extravagantes para nuestra cultura jurídica como los círculos de sentencias o las evaluaciones neutrales por expertos. El derecho a justicia primará la posibilidad de elección del ciudadano, según sus preferencias, el tipo de conflicto o litigio, la capacidad económica, los condicionamientos temporales de carácter personal o profesional que concurran. El derecho de elección del ciudadano, el ejercicio de la libre autonomía de la voluntad, encaja perfectamente en un sistema de justicia pública que oferte distintas alternativas en relación de equivalencia funcional, esto es, en cuanto al resultado final que le ofrecen al ciudadano: acceder a una tutela efectiva de sus derechos y la obtención de una solución justa a los mismos. La referida Sentencia del Tribunal Constitucional, 1/2018, defiende implícitamente, a nuestro entender, ese peso que ha de reconocerse a la libertad de elección (autonomía de la voluntad) del ciudadano a la hora de determinar la vía por la cual desea, y considera más apropiada, la resolución de sus conflictos y litigios, superando en cierto modo el contextualismo literal interpretativo del derecho a la tutela de los derechos en vía judicial, cuando justifica que "no cabe entender que, por el hecho de someter voluntariamente determinada cuestión litigiosa al arbitraje de un tercero, quede menoscabado y padezca el derecho a la tutela judicial efectiva que la Constitución reconoce a todos. Una vez elegida dicha vía, ello supone tan sólo que en la misma ha de alcanzarse el arreglo de las cuestiones litigiosas mediante la decisión del árbitro y que el acceso a la jurisdicción —pero no su 'equivalente jurisdiccional' arbitral, SSTC 15/1989, 62/1991 y 174/1995 - legalmente establecido será sólo el recurso por nulidad del Laudo Arbitral y no cualquier otro proceso ordinario en el que sea posible volver a plantear el fondo del litigio tal y como antes fue debatido en el proceso arbitral".

En esta misma línea de pensamiento, TARUFFO ${ }^{32}$ determina que las distintas alternativas posibles, incluso la jurisdiccional han de tener el mismo nivel de eficiencia. Cualquiera que sea la opción legalmente contemplada, y aplicada por el ciudadano, para la resolución de sus litigios, ha de tener la capacidad de disponer solución al conflicto que los ciudadanos conducen a ellas para conseguir el efecto deseado: justicia, dar a cada uno lo que le corresponde dentro de la legalidad, sin contravenir normas o prohibiciones jurídicas. Hacemos nuestras también, en las conclusiones, la reflexiones de RAMOS MÉNDEZ 33 en cuanto que “administrar justicia no es únicamente decidir casos”, sino que hemos de plantearnos en la sociedad actual que administrar justicia es, en primer término, poder decidir la forma de obtener esa justicia, mediante la elección de la vía que se considera más efectiva para conseguirla. Propo-

32 Taruffo, M., "Una alternativa a las alternativas: patrones para la solución de conflictos", Jueces para la democracia, núm., 60, 2007, pp. 91-101, exponiendo que "es preciso que los legisladores garanticen la eficiencia y la accesibilidad de la justicia pública sólo si se da esta condición, será legítimo permitir que las partes elijan otros métodos para la solución de sus controversias. En cambio, si la justicia pública no es accesible y no es eficiente, esto no sólo supone una violación gravísima de las garantías constitucionales, sino que transforma las alternativas en remedios necesarios e inevitables y, por lo tanto, ya no serían objeto de una elección libre y discrecional de las partes"

33 Ramos Méndez, F., El sistema procesal español, Ed. Atelier, Barcelona, 2010, p. 30

N. ${ }^{\circ} 106$, septiembre-diciembre 2019, págs 13-42 
nemos con ello un derecho nuevo, más amplio e integrador que el actual derecho a la tutela judicial efectiva, más vinculado al caso concreto y al sujeto que garantiza libertad de elección e igualdad e imparcialidad en la forma de obtención de justicia

El derecho a justicia, muestra una nueva faz ${ }^{34}$ de la justicia, entendida desde la previsión de reforma constitucional de futuro que hemos planteado y que habría de asentarse sobre el sustrato de ofrecer un abanico de alternativas completo (de naturaleza judicial y extrajudicial) en sintonía con los nuevos recursos de gestión personal de los derechos (acceso a nuevas tecnologías de la información y la comunicación) y la cultura vigente de la autogestión y el gran margen de discrecionalidad de una expansiva utilización de la autonomía de la voluntad en el ámbito jurídico personal e individual (salvo en casos excepcionales). Modelo que además podría llegar a deparar una diferente concepción general de la Administración de la justicia, plasmada en la reconversión de los actuales "Juzgados y Tribunales” en Domus Iustitiae o “Tribunales Multipuertas” en los cuales se acogerían institucional y materialmente todas las opciones que facilitarían el derecho a justicia al ciudadano, ubicando en una misma sede los diferentes mecanismos procesales para la resolución de conflictos admitidos legalmente (proceso judicial, arbitraje, mediación, conciliación, etc.) en línea con las experiencias y funcionamiento de los ya establecidos en algunos países del mundo anglosajón.

Evidentemente, no podemos olvidar nuestro compromiso jurídico con las garantías legales que el ciudadano debe poder disfrutar. Y por ello entiendo que la mayor, y mejor, garantía que se puede conferir al derecho a justicia es su consideración como derecho fundamental, propugnando la sustitución, mediante la pertinente reforma en el art. 24 de la Constitución Española, del vigente "derecho a la tutela judicial efectiva”, en cierto modo en vías de agotamiento, por el reconocimiento como derecho fundamental de todos los ciudadanos del derecho a justicia, entendido, de forma primigenia, como el derecho de todos y cada uno de los ciudadanos a elegir y utilizar en la forma legalmente prevista, con la garantía y seguridad jurídica normativamente dispuesta por el Estado, los diferentes medios de resolución de conflictos y litigios integrados en el ordenamiento interno del Estado de acuerdo a las condiciones, requisitos, presupuestos, procedimientos y efectos preestablecidos por la Ley.

La superación del derecho constitucional procesal a la tutela judicial efectiva puede, y debe, venir dada de forma innovadora, integradora y realista por la inclusión en una hipotética reforma constitucional del derecho a justicia, como derecho integral para todas las formas legalmente admitidas y reguladas en el Estado de tutelar los legítimos derechos e intereses individuales y obtener justicia, sea a través de mecanismos jurisdiccionales o extrajudiciales. Es momento de cambio y de mudanza, de adaptación a nuevas realidades jurídicas y a nuevos retos de la sociedad del siglo XXI, a su cultura y a sus propuestas. A ellas, el Derecho, nuestro inveterado guion de convivencia pacífica y en sociedad, ha de dar respuesta constitucional con la efectividad

34 Costa e Silva, P., A nova face da justiça. Os meios extrajudiciais de resoluçao de controversias, Coimbra Editora, 2009 
de siempre. Bienvenido sea, más pronto que tarde, el derecho a justicia, como evolución imprescindible y natural de nuestro constitucionalizado y sempiterno derecho a la tutela judicial efectiva.

Title:

The fundamental Right to Justice: Comprehensive revision of the Right to effective judicial protection.

\section{Summary:}

I.- Approach for evolution towards an integral and integrating fundamental right to the effective protection of subjective rights. 1.- What is "justice"? 2.- A broader concept of justice claims a fundamental integrating right: precedents. II.- The right of access to justice as human and fundamental right. III.- The Administration of justice from the integrating and integral vision of the right to justice. IV.- Constitutional procedural profile of the right to justice. 1.- Notion and application of fundamental procedural right to justice. 2.- Legal constitutional elements that shape the right to justice. V.- Conclusion and final proposal

\section{Resumen:}

El derecho a la tutela judicial efectiva, siendo uno de los derechos de máxima relevancia constitucional, no ha de mantenerse estático, sino que puede evolucionar hacia una vertiente más integradora, dando cabida a las pujantes formas extrajudiciales de resolución de litigios. En ese sentido el presente trabajo propone una evolución del actual derecho, recogido en el art. 24 de la Constitución Española, hacia un derecho fundamental que ofrezca, en su texto y aplicación, todas las variantes de resolución de litigios al justiciable, sean judiciales o extrajurisdiccionales y con ello garantice su consideración global como forma de obtener justicia, junto a la tradicional solución judicial del litigio. La Administración de justicia del siglo XXI, en conexión con la realidad social y el auge de los medios extrajudiciales de resolución de litigios (arbitraje, mediación, conciliación, negociación), ha de sostenerse en el futuro sobre un derecho fundamental a justicia, un derecho de la máxima categoría legal que habilite a que el ciudadano elija libremente la vía de solución del litigio considera más adecuada para la efectiva protección de sus derechos e intereses. En el trabajo se presentan las características y concepto de este posible nuevo derecho fundamental, más amplio e integrador que el actual derecho a la tutela judicial efectiva, 
y conectado directamente con la cultura de autogestión y discrecionalidad en la aplicación de los derechos subjetivos, lo cual, además, supondrá un nuevo modelo de Administración de justicia, en el cual se incorporen como complementos al proceso todas la opciones extrajudiciales de resolución de litigios que contemple la legislación vigente.

\begin{abstract}
:
The right to effective judicial protection, being one of the rights of maximum constitutional relevance, must not remain static but may evolve towards a more integrative side, giving rise to the powerful extrajudicial forms of alternative dispute resolution (ADR). In this sense, the present work proposes an evolution of the current right, included in art. 24 of the Spanish Constitution, towards a fundamental right that offers, in its text and application, all the possibilities of litigation to the litigant (judicial or out-of court) and with this guarantee its global consideration as a way to obtain justice, together with the traditional judicial solution of the litigation. The Administration of justice of the XXI century, in connection with the social reality and the rise of extrajudicial means of resolving litigation (arbitration, mediation, conciliation, negotiation), must be sustained in the future on a fundamental right to justice, right of the maximum legal category that enables the citizen to choose freely the solution to the litigation considered most appropriate for the effective protection of their rights and interests. The work presents the characteristics and concept of this possible new fundamental right, broader and more inclusive than the current right to effective judicial protection, and directly connected with the culture of self-management and discretion in the application of subjective rights, which, in addition, it will suppose a new model of Administration of justice, in which all the out-of-court options of litigation will be contemplated by the current legislation and will be incorporated as complements to the process.
\end{abstract}

\title{
Palabras clave:
}

Derechos Fundamentales; Tutela judicial efectiva; Justicia; Medios extrajudiciales de resolución de litigios

Key words:

Fundamental rights; Right to effective judicial protection; Justice; ADR 